\title{
ABC Implementation in Chinese Manufacturing Firm: A Case Study in a Small and Medium Sized Firm
}

\author{
Yu. Liu \& Y.F. Zhang \& W. J. Li \& Y.Y. Zhu \\ University of Cheng Du
}

\begin{abstract}
Activity-Based Costing $(\mathrm{ABC})$ system is designed to address the shortcomings of traditional volume based costing system. Up to date, number of studies conducted in Small-Medium Sized Enterprises (SMEs) about ABC implementation is relatively small. Therefore, this study conducts a case study in one Medium sized manufacturing firm in Sichuan province with aims to 1) identify differences in terms of profit produced by company's current costing system and $\mathrm{ABC}$ system; 2) to design $\mathrm{ABC}$ system for the selected company; as well as 3) to suggest how to implement ABC system successfully in the selected company. KEYWORD: Activity-Based Costing System; Small-Medium Sized Enterprise; Case study
\end{abstract}

\section{INTRODUCTION}

Activity Based Costing (ABC) system is designed to address the shortcoming of traditional volume based costing system (Cooper \& Kaplan, 1988). Instead of using single cost driver, $\mathrm{ABC}$ system adopts multiple cost drivers to trace overhead costs to final products or services.

Motivated by the merits of $\mathrm{ABC}$ system, number of researchers has been undertaking studies about how to implement $\mathrm{ABC}$ system successfully, and factors influencing $\mathrm{ABC}$ adoption and so on. However, case studies about $\mathrm{ABC}$ implementation and its potential benefits were only undertaken in large sized enterprises. Studies conducted among Small and Medium Sized Enterprises (SMEs) are still remain largely unexplored.

Thus, this study conducted a case study in a Small-Medium Sized manufacturing firm, and the objectives of this study are 1) to identify differences in terms of profit produced by company's current costing system and $\mathrm{ABC}$ system; 2) to design $\mathrm{ABC}$ system for the selected company; and 3) to suggest how to implement $\mathrm{ABC}$ system successfully in the selected company.

The structure of this study is as follow: the background of the selected company is presented in the section 2, and then followed by the design of $\mathrm{ABC}$ implementation in selected company in section 3. Finally, the conclusions and suggestions for the selected company are highlighted in section 4 .

\section{COMPANY BACKGROUND}

ZiRongHuayu knitting Company was found in 2002. It locates in Chengdu city, China. The company produces a wide range of woollens related products. The company specializes in producing the spinning woollen products such as cashmere. In the financial year of 2012, the company generated total annual revenue of RMB20 000000 and a net profit of RMB1 000000 in its major national market.

In 2013, the operating environment of knitting industry experienced profound changes. One of effects from operating environment came from the worldwide financial crisis. Worldwide financial crisis decreased the demand from overseas for knitting products, as well as the demand for outsourcing. Drop in demand from overseas decreased revenue significantly.

Apart from worldwide financial crisis, knitting industry is facing the inflationary pressure and intensively market competition domestically. Inflation causes rapidly rise in material prices and it further decreases the profit margin of knitting industry. Due to the intensified competition in the industry $\mathrm{ZiRongHuaYu}$ is operating, top management realizes that managing its operating cost is considered as the key approach to improve its competitive advantages over its competitors. Currently, ZiRongHuaYu's product cost consisted of direct material, direct labour and manufacturing overhead. Under company's current costing system, unit cost for its major products, namely, 12-Gauge Cashmere, 14-Gauge Wool, 16-Gauge Lyocell, 16- 
Gauge Worsted Cashmere, as well as 16-Gauge Silk Cashmere were RMB476.33, RMB322.76, RMB295.14, RMB665.60, as well as 450.26 respectively. However, top management of ZiRongHuaYu Company could not confirm that whether the existing costing system could actually reflect the true production cost.

In order to improve company's performance, especially the accuracy of the existing costing system, Top management of ZiRongHuaYu attempted to adopt advanced management accounting practices, especially, the practices have been successfully implemented in Western countries. About half a year ago, manager of ZiRongHuaYu hired two consultants from University of Chengdu to suggest suitable management accounting practices to improve company's current accounting techniques. After interviewing with finance managers, production managers, consultants realized that ZiRongHuaYu applied inappropriate method to allocate overhead costs to final products. The allocation basis of the company's current costing system is direct labour hours. Therefore, consulting team recommended Activity-Based Costing (ABC) system to top management of the company.

Consulting team highlighted the two main reasons for ZiRongHuaYu to adopt $\mathrm{ABC}$ system: 1) High amount of overhead. In ZiRongHuaYu, the overhead cost makes up over $50 \%$ of the total cost, ABC system is suitable when the overhead costs accounts for high percentage of total cost. 2) Product diversity. More products manufactured by a firm, the higher percentage of overhead costs would be accounts for the total cost. In ZiRongHuaYu, the raw materials of company consist of over 20 different woollens, and the different raw materials are used to produced more than thousands of product. Therefore, the possibilities of overhead would be high.

Consulting team also explained the benefits of $\mathrm{ABC}$ system and how $\mathrm{ABC}$ system could be used to improve the overall accuracy of costing information to top management of $\mathrm{ZiRongHuaYu}$ Company. Finally, top management of ZiRongHuaYu decided to employ $\mathrm{ABC}$ system to enhance its abilities to control operating cost.

\section{ABC IMPLEMENTATION IN ZIRONGHUAYU COMPANY}

After top management was convinced to adopt costing system, consulting team aimed to design a framework for ZiRongHuaYu Company to implement $\mathrm{ABC}$ system. During this stage, interviews and observations were employed to collect research data. The five major products manufactured by ZiRongHuaYu are: 12-Gauge Cashmere, 14-Gauge Wool, 16-Gauge Lyocell, 16-
Gauge Worsted Cashmere, as well as 16-Gauge Silk Cashmere.

According to Akyol (2004, p. 55), the process of $\mathrm{ABC}$ implementation stage could be concluded as follows:

1) Identifying the key activities of organizations, such as engineering, machining, inspection.

2) Determining the activity costs.

3) Selecting the appropriate cost drivers, such as direct labor, machine hours, and number of set up.

4) Collecting activity data.

5) Calculating product or service cost.

\subsection{Identify key activities}

Based on the discussion with top management, consulting team outlined the core manufacturing activities of ZiRongHuaYu Company: 1) material procurement, 2) preparation process, 3) order entry, 4) garment manufacturing, 5) quality inspection, 6) ) mosaic and sewing of garment piece, collar, 7) afterfinishing for textile product, 8) inventory sorting, 9) packing and transporting, and 10) inventory storage.

\subsection{Identifying of Activity cost}

After the identification of the core activities of Company ZiRongHuaYu, consulting team computed the resources consumed by each activity in monetary terms.

Overhead costs are considered as activity cost. Major overheads incurs in a ZiRongHuaYu are indirect labour, indirect materials, factory depreciation and so on.

Order entry is the first step of production process. The costs incurred in this stage were: salary paid to the staff in charge of this work, purchasing of relevant materials. Therefore, total amount of order entry expenses need to trace to final products are RMB229, 168.

The second activity is preparation process including order programming. The overheads incurs in this stage were compensation paid to relevant staff, as well as expenses spent on designing during the process of preparation. According to the accounting record of ZiRongHuaYu, the total amount incurred on preparation process equals RMB345, 999.96, which must be allocated among different type of products.

For the activity of and mosaic and sewing of garment piece and collar, it consumes labour resources. The expenses incurred on this activity comprised of salaries paid to staff in charge of this work, materials consumed. Due to it related to the production, thus, consulting team regarded it as indirect labour. Therefore, the amount of sewing expenses was RMB 1,841,960.04.

Quality inspection expenses were the salaries paid to employees involved in that task during the process 
of inspection. Consulting team consider quality inspection expenses was indirectly related to the production process, therefore, it should be classified as indirect labour. Hence, the total amount inspection expenses needed to be allocating finished products are RMB247, 652.

The activity costing of manual processing was consisted of salaries paid to relevant employees and materials used. Therefore, this activity consumed labour and indirect material. Consulting team calculated manual processing expenses amounted to RMB108, 291.96.

As for the activity of inventory sorting, packing and transporting, the overhead costs component consisted of salaries paid to people involved and indirect material consumed, transporting fees. Consulting team calculated that expenses for sorting, packing and transporting were totalled by RMB 531,578.60.

During the production process, in ZiRongHuaYu, fuel was an important energy, and it was used in the whole production process. Thus, consulting team firmly believed that fuel expenses should be traced to final products.

Finally, the all the finished products were sent to the warehouse of ZiRongHuaYu. Therefore, expenses spent on the activity of inventory storage were salaries paid to people responsible for inventory storage, insurance paid, utilities paid, as well as depreciation charges on warehouse. Consulting team figured out that the total amount for inventory storage were $1,437,196.00$.

Apart from major activities, other overheads needs to be allocated to finished products were: Depreciation expenses on plant and factory, rental fees paid on factory. They are all needed to be traced to the major products of $\mathrm{ZiRongHuaYu}$.

\subsection{Selection of Cost Driver}

Cost driver is considered as the basis to allocate overhead cost. After figuring out the key activities of ZiRongHuaYu Company, the next step is to select suitable allocation basis to trace overhead.

For the activity of preparation process, the cost driver is selected as labour hours, because it consumes labour hours. Therefore, the allocation basis for should be number of writing. In ZiRongHuaYu, each product must be written, therefore, number of writing was the same with production volume.

Cost driver for the activity of quality inspection is identified as number of inspections. The work of inspections consumes labour hours. According to ZiRongHuaYu's total quality control policy, all the finished products are required to conduct the quality inspection, thus, the number of inspections are the same with the production volume. Number of quality inspections for the product of 12-Gauge Cashmere,
14-Gauge Wool, 16-Gauge Lyocell, 16-Gauge Worsted Cashmere, as well as 16-Gauge Silk Cashmere are 4635, 1700, 495, 772, and 196 respectively.

Cost driver for the activity of manual processing is the units produced. In $\mathrm{ZiRongHuaYu}$, each type of garment is requested by further processed by skilled employees, therefore, the suitable allocation for manual processing fees is units produced.

The activity of mosaic and sewing of garment piece, collar consumes the labour hours, and necessary materials used in the sewing and mosaic. Consulting team recommended that cost driver was also unit produced. In ZiRongHuaYu, each garment must be sewed, therefore, the appropriate cost driver for sewing is unit produced.

In $\mathrm{ZiRongHuaYu}$, each finished goods are requested to be packed, sorted, and transported, thus, consulting team recommended company to select units produced as the allocation basis to allocate packaging, transporting fees.

Other activity of ZiRongHuaYu is inventory storage, and this activity is related to production volumes. Thus, appropriate cost driver should be units produced of each product.

As it is mentioned in the last section, fuel was used during the whole process of production in $\mathrm{ZiRongHuaYu}$, therefore, consulting team suggested top management to adopt total unit produced in 2013 as the cost driver for fuel expenses.

Also, according to the internal control of ZiRongHuaYu, each unit of finished goods should be entered into order, so consulting team advised that the appropriate cost driver for the activity of order entry should be the actual production volume.

Furthermore, factory rental fees, as well as depreciation on plant, facilitate and equipment. After discussion with top management of ZiRongHuaYu, consulting team suggested to adopt production volume as the allocation basis.

To sum up, due to the special characteristics, the suitable cost driver for all the major activities were: production volume in the year of 2013.

\subsection{Calculating Product Cost}

After figuring out the activity costs and selection of cost drivers, the next step was to calculate the allocation rate. The allocation rate could be calculated by using each activity cost divided by its relevant allocation basis. In ZiRongHuaYu Company, the product cost equals direct materials plus direct labour, as well as manufacturing overhead.

For the allocation rate for order entry, the total amount was RMB229,168.00, and the total production volume in the year of 2013 were 31,192. Thus, the allocation rate should be RMB229,168.00/31,192=7.3470, thus, order entry expenses allocate to the12-Gauge Cashmere, the 14- 
Gauge Wool, the 16-Gauge Lyocell, the 16-Gauge Worsted Cashmere and the 16-Gauge Silk Cashmere were: RM136,213.60, RMB49,956.68, RMB14,547.08, RMB22,687.57 and RMB5,760.06 respectively.

For the activity cost of manual processing, the allocation rate was computed by the total amount of salaries paid dividing by total units produced, thus, allocation rate was 3.4718. Then, the exact amount needed to be traced to each product could be calculated by using production volume of each product multiply by the allocation rate. Thus, manual process expenses for the product of 12-Gauge Cashmere, 14-Gauge Wool, 16-Gauge Lyocell, 16Gauge Worsted Cashmere and the 16-Gauge Silk Cashmere were RMB64,366.92, RMB23,608.15, RMB6874.14, RMB10,720.88, and RMB2721.88 respectively.

As for the overhead of sewing and mosaic, the total amount needs to be beard among all the finished products were RMB1, 841,960.04. The calculation for allocation rate could use total amount of expenses spent on this activity divide by units produced in the year 2013. After computation, consulting team realized that the overhead of sewing and mosaic should be traced to the main products of 12-Gauge Cashmere, 14 -Gauge Wool, 16-Gauge Lyocell, 16-Gauge Worsted Cashmere and the 16Gauge Silk Cashmere were RMB1,094,830.06, RMB401,555.79, RMB116,923.60, RMB182,353.57, and RMB46,297.02 respectively.

The total amount overhead costs for inventory sorting, packing and transporting were RMB531, 578.60. And the allocation basis was also total production volume in the 2013. Hence, amounts allocated to the 12-Gauge Cashmere, the 14-Gauge Wool, the 16-Gauge Lyocell, the 16-Gauge Worsted Cashmere and the 16-Gauge Silk Cashmere were RMB315, 961.38, RMB115, 886.59, RMB33,743.45, RMB52,626.15 and RMB52,626.15 respectively.

Total amount fuel expenses were figured out by the amount of RMB156, 891.36. 12 -Gauge Cashmere beard the expenses of fuel expenses by RMB93, 253.58, 14-Gauge Wool should be allocated by the amount of RMB34, 203.04, RMB9,959. 12 should be traced to the 16-Gauge Lyocell. While, the 16-Gauge Worsted Cashmere should bear the fuel expenses by RMB15, 532.20. In addition, the amount of fuel expenses for the 16-Gauge Silk Cashmere was calculated as RMB3, 943.41.

Total amount of quality inspection expenses were computed by RMB247, 692. The approach of figuring out the allocation rate was the same with the allocation rate of other overheads. Among the five main products, due to the production volume, the highest amount of quality inspection expense was allocated to the 12-Gauge Cashmere (RMB147, 223.96). Followed by the 14-Gauge Wool (RMB53, 998.00), the 16-Gauge Lyocell (RMB15, 722.95), the 16-Gauge Worsted Cashmere (RMB24, 521.44), and then the lowest amount was allocated to 16Gauge Silk Cashmere (RMB6, 225.65).

Total costs spent on inventory storage were RMB1, 437,196.00. The allocation rate for this activity cost equalled 7.9409 (RMB1, 437,196.00/31,192 units). Therefore, inventory storage costs for the main products: 12-Gauge Cashmere, 14-Gauge Wool, 16-Gauge Lyocell, 16Gauge Worsted Cashmere, as well as 16-Gauge Silk Cashmere were RMB854,245.12, RMB313,315.36, RMB91,230.06, RMB142, 282.04 and RMB36, 123.42 respectively.

The activity cost for preparation process amounted to RMB345, 999.96. The allocation rate was calculated as 11.0926. Thus, the amount of RMB205, 656.55 should be traced to the product of 12-Gauge Cashmere. 14-Gauge Wool should bear the expenses by RMB75, 429.59. And the amounts needed to be allocated to the product of 16-Gauge Lyocell, 16-Gauge Worsted Cashmere and 16-Gauge Silk Cashmere were RMB21, 963.32, RMB34, 253.91 and RMB8, 696.59 respectively.

Furthermore, overhead costs incurred in the year of 2013 were also consisted of factory rental fees, depreciation charges on plant and equipment. The method of figuring out allocation rate was the same: using the relative amount divided by the total units produced in 2013.

Overhead costs needed to be allocated to each main products had been confirmed, and direct labour and direct material could be directly traced to main products, and finally, consulting team figured out that unit costs for the product of 12-Gauge Cashmere, 14-Gauge Wool, 16-Gauge Lyocell, 16-Gauge Worsted Cashmere, as well as 16-Gauge Silk Cashmere were RMB504.60, RMB351.03, RMB323.41, RMB693.87 and RMB478.53 respectively.

Top management realized that cost per unit for the main products could be accurately reflected by $\mathrm{ABC}$ system, The cost per unit of 12-Gauge Cashmere, 14-Gauge Wool, 16-Gauge Lyocell, 16Gauge Worsted Cashmere, as well as 16-Gauge Silk Cashmere were understated by $5.93 \%, 8.76 \%, 9.58 \%$, $4.25 \%$ and $6.28 \%$ respectively.

\section{SUGGESTIONS FOR ZIRONGHUAYU COMPANY}

Since top management of ZiRongHuaYu decided to implement $\mathrm{ABC}$ system, consulting team provided some practical suggestions regarding to how to implement $\mathrm{ABC}$ successfully.

Firstly, top management ZiRongHuaYu Company should provide sufficient support to the implementation of ABC system. Numerous studies showed that top management support is crucial 
factors in determining the $\mathrm{ABC}$ implementation success (Lana \& Fei, 2007; Majid \& Sulaiman, 2008; Shields, 1995; Shields \& McEwen, 1996).This kind of support includes providing adequate funds to the implementation process. And top management should allocate all the necessary resources to the $\mathrm{ABC}$ project.

Secondly, adequate training also should be provided to employees in ZiRongHuaYu Company. China is classified by Hofstede (1984) as "high uncertainty avoidance" culture. Brewer (1998, p. 242) stated that high uncertainty avoidance as a measure of the degree to which cultures feel uncomfortable with uncertainty and ambiguity". Brewer (1998) highlighted that employee in Asian context needs more training compare to employees in Western society. Furthermore, Shields (1995) stressed that during the training not only employees are educated but also their feeling of threatened could be minimized. Therefore, in $\mathrm{ZiRongHuaYu}$ Company, training courses should be supplied to employees regarding the step of ABC implementation, as well as the factors influencing ABC implementation success. Top management of ZiRongHuaYu also should share their knowledge of $\mathrm{ABC}$ system and its benefits among employees, thus, the understanding of $\mathrm{ABC}$ system among employees might be enhanced.

Shields (1995) and Baired et al (2007) pointed out that employees could be motivated to participate into the $\mathrm{ABC}$ implementation process by linking their performance evaluation and compensation to ABC implementation. Drake et al (2001) concluded that an effective way to motivate existing employees to implement $\mathrm{ABC}$ is to link performance measure and evaluation to the information supplied by $\mathrm{ABC}$ system. Hence, top management of Company should be suggested to take ABC implementation as part of employees' performance evaluation and compensation. The system of performance measure and compensation in Company should be designed to encourage the existing staff to participate into the ABC system implementation process. Once, employees are motivated, the likelihood of $\mathrm{ABC}$ implementation success would be enhanced.

\section{REFERENCES}

[1] Baird, K. M., Harrison, G. L., \& Reeve, R. C. (2007). Success of activity management practices: the influence of organzational and cultural factors. Accounting and Finance, 47(1), 47-67.

[2] Brewer, P. C. (1998). National culture and activity-based costing system: a note. Management Accounting Research, 9, 241-260.

[3] Cooper, R. \& Kaplan, R. (1988). How Cost Accounting Distorts Product Costs. Management Accounting, April, 20-27

[4] Drake, A., Haka, S. F., \& Ravenscroft, S. P. (2001). An ABC Simulation Focusing on Incentives and Innovation. Issues in Accounting Education, 16(3), 443-471.

[5] Hofstede, G. (1983). The Cultural Relativity of Organizational Practices and Theories. Journal of International Business Studies, 14(2), 75-89.

[6] Lana, Y. J. L., \& Fei, P. (2007). The implementation of Activity-Based Costing in China: An innovation action research approach. The British Accounting Review, 39(3), 249-264.

[7] Majid, J. A., \& Sulaiman, M. (2008). Implementation of activity-based costing in Malaysia: A case study of two companies. Asian Review of Accounting 16(1), 39-55.

[8] Shields, M. D. (1995). An Empirical Analysis of Firms' Implementation Experiences with Activity-Based Costing Management Accounting Research 7, 148-166.

[9] Shields, M. D., \& McEwen, M. A. (1996). Implementing activity-based costing systems successfully. Cost Management, 9(4), 15-22. 